The following day was spent in Utrecht, a city with an old university and an excellent medical school. Again we were delighted by the versatility of our host who was a general surgeon in its widest sense, who could teach us much, yet was ever willing to listen. A delightful evening at our host's home in a fine old house, with the water lapping against its walls, ended a memorable day. To conclude our visit we drove out to the great dyke which makes the Zuyder Zee a fresh water sea by shutting it off from the ocean. The scenery, utterly flat and not even relieved by a windmill, soon lost its novelty and one could well imagine that in time it would engender agerophobia in the staunchest. There were depressing signs of German wantonness in the skeletons of wooden houses made uninhabitable by flooding. The dykes were destroyed as they retreated in I945, not long before the surrender. However the Dutchman has not earned his reputation for stubbornness without cause and already a most ambitious rebuilding programme is well on the way to completion.

The Dutch, even as ourselves, seem to take the problem of recovery after the war very seriously, and in fact in some ways have been more successful than us. We have much in common and it is hoped that the exchange of medical knowledge and of doctors in the future will be even greater than in the past.

\section{Aid for the Deaf}

It is gratifying to learn that a committee has been set up to consider the three aspects of therapyfor the deaf. Medical, surgical and instrumental The greatest advances in these three aspects has been made in the surgical treatment of otosclerosiso and in the construction of the present-day crysta $\overline{\bar{p}}$ microphone, with miniature valve amplifier $\varrho$ hearing aid.

The surgical approach is, of course, to be under $\vec{\circ}$ taken only by those taking the trouble to perfectw the difficult technique, and the operation has no doubt come to stay, for its place in the treatment of otosclerosis is now proven without any doubti

Although advances have been made in these three branches of therapy for the deaf, there stillw remains to be formed in this country, clinics se? apart entirely for the treatment of the deaf, from? infancy to old age. Thus within the one clinic there should be facilities for speech therapy, lip reading, hearing aid selection and maintenance, surgical treatment for those suitable for the ope $\overrightarrow{0}$ tion, medical treatment for those who requiresipo and finally and perhaps most important of facilities for further research in one or all of theses three branches. Such clinics, I believe, are in existence in the Western Hemisphere but not in Europe.

\title{
Paediatric Number
}

The July issue of the Journal was devoted to Paediatrics, but owing to the shortage of paper it was impossible to print all the articles. This month Dr. J. L. Henderson's paper on 'Infection in the Newborn Infant' has therefore been included in addition to the published contents.

\section{Correction}

In the article by Dr. I. A. B. Cathie on ' The Streptomycin Treatment of 'Tuberculous Meningitis ' appearing in last month's issue of the Journal a typographical error occurs beneath a number of illustrations. In Figures I and II, c.2 gm. per lb. of body weight should read : $0.02 \mathrm{gm}$. per lb. of body weight. In Figures III and V, O.I gm. per lb. of body weight should read : o.or gm. per lb. of body weight. We apologise for this error and hope that it has not proved misleading. 